\title{
Altered Expression Patterns of EphrinB2 and EphB2 in Human Umbilical Vessels and Congenital Venous Malformations
}

\author{
STEFANIE DIEHL, ROXANA BRUNO, GEORGE A. WILKINSON, DIRK A. LOOSE, \\ JÖRG WILTING, LOTHAR SCHWEIGERER, AND RÜDIGER KLEIN
}

\begin{abstract}
Max-Planck Institut für Neurobiologie [S.D., R.B., G.A.W., R.K.], D-82152 Martinsried, Germany; Abt. Pädiatrie I [S.D., J.W., L.S.], Zentrum für Kinderheilkunde und Jugendmedizin, Bereich Humanmedizin der Universität Göttingen, D-37075 Göttingen, Germany; and Zentrum für Gefässmedizin [D.A.L.], D-22761 Hamburg, Germany
\end{abstract}

\begin{abstract}
Vascular malformations cause discomfort and pain in children and are often associated with skeletal hypertrophy. Their molecular basis is poorly understood. Ephrin ligands and Eph receptor tyrosine kinases are involved in embryonic vascular development. In mice, some ephrin/Eph family members show a complementary expression pattern in blood vessels, with ephrinB2 being expressed on arterial and EphB4 on venous endothelium. Targeted deletions of the genes reveal their essential roles for conduit vessel development in mice, suggesting similar functions during human vascular development and deregulation in vascular malformations. Here, we have defined the expression patterns of human ephrinB2, EphB4, and EphB2 in normal vessels of neonates (i.e. umbilici) and adults and compared them with those in congenital venous malformations. In adults, normal vessels of the skin, muscle, and legs express ephrinB2 and EphB2 on arterial endothelial cells (ECs), whereas EphB4 is
\end{abstract}

\section{ABSTRACT}

found in arteries and veins. In the umbilicus, EphB2 is a specific marker of arterial ECs, whereas ephrinB2 is additionally expressed in venous ECs, suggesting an arterial function of the veins. In venous malformations, the expression of EphB4 is not altered, but both ephrinB2 and EphB2 are ectopically expressed in venous ECs. This may reflect a nonphysiologic arterialization of malformed veins. Our study shows that the arterial markers ephrin B2 and EphB2 are expressed in a subset of veins, and it remains to be studied whether this is cause or consequence of an altered vascular identity. (Pediatr Res 57: 537-544, 2005)

EC, endothelial cell

\section{Abbreviations}

SAM, sterile $\alpha$ motif

$\boldsymbol{\alpha}$-SMA, $\alpha$-smooth muscle actin

SMC, smooth muscle cell
During embryogenesis, blood vessels form via two distinct processes, vasculogenesis and angiogenesis (1-5). Vasculogenesis involves the de novo development of endothelial cells (ECs) from mesodermal precursors, the angioblasts, and leads to the formation of the early vascular plexus. Later, blood vessels arise mainly from the preexisting ones by sprouting, splitting, and intussusceptive growth of capillaries in a process called angiogenesis. Remodeling of the primary vascular plexus into conduit vessels and capillaries ensures perfusion of all organs and tissues with blood. In the adult, angiogenesis accounts for neovascularization accompanying cyclic repro-

Received January 15, 2004; accepted August 19, 2004.

Correspondence: Lothar Schweigerer, Abt. Pädiatrie I (Hämatologie/Onkologie), Zentrum für Kinderheilkunde und Jugendmedizin, Bereich Humanmedizin der Universität Göttingen, Robert-Koch-Strasse 40, D-37075 Göttingen, Germany; e-mail: Lothar.Schweigerer@med.uni-goettingen.de.

This study was supported by grant DI $832 / 1-1$ from the Deutsche Forschungsgemeinschaft.

DOI: 10.1203/01.PDR.0000155761.70710.C4 ductive changes in women, as well as pathologic processes such as tumor growth, diabetic retinopathy, and rheumatoid arthritis $(6,7)$.

To date, three growth factor families have been identified as critical players of blood vessel development: vascular endothelial growth factors, angiopoietins, and ephrins $(8,9)$. Unlike vascular endothelial growth factors and angiopoietins, which are secreted proteins, ephrins are attached to the plasma membrane and function in cell-cell communication (10). Ephrins can be divided into two subclasses: EphrinA ligands (ephrinA1-A5) are tethered to the outer cell surface via a glycosylphosphatidylinositol anchor, whereas ephrinB ligands (ephrinB1-B3) possess an extracellular, a transmembrane, and a conserved cytoplasmic domain. This subdivision also matches the binding preferences of ephrin A and ephrinB ligands to the corresponding EphA and EphB receptor subfamilies, respectively, whereas within these subfamilies, interactions are highly promiscuous. Eph receptors and ephrin ligands are involved in many important biologic processes. They regulate 
axon guidance and fasciculation in the developing brain and control cell migration, adhesion, and pattern formation in the embryo (11). Although the functions of Eph receptors and their ligands have been studied to some extent in the nervous system, their functions in the vasculature are not well understood.

Recent studies from targeted disruption of Eph receptors and ligands in mice, together with studies in vitro, indicate a dual role of Eph signaling for sprouting angiogenesis and blood vessel remodeling. Mouse embryos lacking ephrinB2 or EphB4 exhibit fatal defects of conduit vessels formed during early vascular remodeling $(12,13)$. Furthermore, elevated expression of Eph receptors and ephrin ligands promotes tumor angiogenesis and tumor growth $(14,15)$. In mice, ephrinB2 and EphB4 display a remarkably reciprocal expression pattern within the developing vasculature, ephrinB2 being expressed in arterial and EphB4 in venous ECs (12). Although subsequent studies have described low levels of EphB4 also on arterial ECs (13), ephrinB2 and EphB4 are excellent markers for arterial and venous ECs even at very early stages of development.

The finding that ephrinB2 and EphB4 are crucial for the development of conduit vessels in mice has prompted us to investigate their expression in human vascular malformations. These may be derived from capillary, venous, arterial, and lymphatic channels or combinations thereof (16). The malformations increase in size proportionally to the growth of the patient and, unlike hemangiomas, never regress spontaneously. The patients experience discomfort and pain. Complications frequently include infection, thrombosis, skeletal hypertrophy, and congestive cardiac failure. The subfascial main vascular routes are often affected. However, malformations may as well occur in smaller vessels anywhere in the body wall and the inner organs (17). The pathogenesis of nonhereditary vascular malformations is unknown, and causal therapies do not exist. Treatment mainly includes embolization, cryosurgery, laser therapy, and surgical resection. Here, we have focused on predominantly venous malformations from patients who have had this disease since their early childhood. We have used antibodies against ephrin/Ephs to characterize the arterial and venous nature of malformed vessels. In parallel, we applied the PAL-E antibody (18), which has often been used to identify veins and leaves arteries unstained.

\section{METHODS}

Tissue samples. Human umbilical cords $(n=10)$ were obtained from healthy subjects immediately after birth. Venous malformations $(n=7)$ were obtained from patients who were admitted for surgery. Subfascial malformed veins were resected from the legs of the patients. Venous malformations were diagnosed by Doppler sonography and radiologic examination. They were of low-flow type. Arteriovenous shunts were excluded from this study. The clinical diagnoses were always confirmed by histologic analysis, where hematoxylin/eosin and elastica staining were used to display predominantly venous vessels with irregular tunica media and focal interstitial fibrosis but without signs of malignant transformation. Patients were aged between 9 and 46 y ( 3 female, 4 male). Control tissues $(n=5)$ included skin, skeletal muscle, and vessels from the leg and were obtained from adults who underwent surgery for reasons other than vascular malformations. All specimens were snap-frozen in isopentane cooled in liquid nitrogen and stored at $-80^{\circ} \mathrm{C}$ until further use. The studies were performed with the informed consent of the patients and were approved by the hospital's ethical committee.

Immunofluorescence staining. Tissue samples were cut into $20-\mu \mathrm{m}$ sections, mounted on Superfrost Plus slides (Menzel-Glaeser, Braunschweig, Germany), and air-dried for $30 \mathrm{~min}$. Tissues were fixed in cold acetone for 5 min and air-dried for another $30 \mathrm{~min}$. Specimens then were incubated in a blocking solution that contained PBS supplemented with $2 \%$ normal goat serum and 2\% BSA. Antibody staining was performed with the following primary antibodies: monoclonal mouse anti-human CD31 (PECAM-1; Research Diagnostics, Flanders, NJ), monoclonal mouse anti- $\alpha$-smooth muscle actin $(\alpha$ SMA; Sigma Chemical Co.-Aldrich, Deisenhofen, Germany), monoclonal mouse antibody PAL-E (Research Diagnostics), polyclonal goat anti-mouse ephrinB2 (R\&D Systems, Abingdon, UK), and polyclonal rabbit anti-mouse EphB2 and EphB4. Antisera that recognize mouse EphB2 and mouse EphB4 were generated using published strategies. Briefly, a cDNA fragment encoding the sterile $\alpha$ motif (SAM) domain of mouse EphB4 (nucleotides 3140-3436 of accession no. XM_109433) or mouse EphB2 (19) was fused to glutathione-S-transferase, and the purified bacterially expressed fusion protein was used as for immunization of rabbits. Specificity and absence of cross-reactivity with other Ephs of the resultant antisera were confirmed by Western blot.

The primary antibodies directed against EphB2 and EphB4 were diluted 1:400, ephrinB2 1:20, CD31 1:40, $\alpha$-SMA 1:3000, and PAL-E 1:200 in blocking solution; applied to the sections; and incubated for $1 \mathrm{~h}$ at room temperature. Sections were washed with PBS three times for $20 \mathrm{~min}$ each and incubated for $1 \mathrm{~h}$ at room temperature with the following secondary antibodies diluted 1:200 in blocking solution: sheep anti-mouse IgG Texas Red (Jackson Laboratories, West Grove, PA) and donkey anti-goat IgG Alexa 488 and donkey anti-rabbit IgG Alexa 488 and Alexa 594 (Molecular Probes, Leiden, The Netherlands). The sections were mounted with fluorescence mounting media (Vector Laboratories, Burlingame, CA) and studied with Zeiss Axioplan 2 epifluorescence microscope.

\section{RESULTS}

In adult humans, ephrinB2 and EphB2 are expressed in arterial ECs, whereas EphB4 is present in arteries and veins. To define the expression patterns of ephrins and Eph receptors in human venous malformations, we first sought to delineate various blood vessel constituents in normal tissue using immunohistochemistry. To identify all ECs or only those present in capillaries and veins, we used antibodies directed against CD-31 (PECAM-1) and PAL-E. The latter do not stain arterial or lymphatic vessels $(18,20)$. To stain the tunica media of arteries and veins, we used antibodies directed against $\alpha$-SMA. Various types of double staining were performed to identify the types of vessels that express ephrinB2, EphB2, and EphB4. Our studies show that ephrinB2 is co-localized in arteries with EphB4 (Fig. 1A-C). EphrinB2 immunoreactivity was seen in CD31-positive endothelium of vessels, which do not express PAL-E (Fig. 1D-I). EphrinB2 immunoreactivity was not observed in PAL-E-positive vessels, i.e. veins (Fig. $1 J-L$ ). Therefore, ephrinB2 seems to be preferentially expressed in arterial ECs. This view is supported by the typical morphology of ephrinB2-positive cells demonstrating their longitudinal orientation toward the blood flow (Fig. 1C). These findings are in line with the expression pattern of ephrinB2 in mice and chicks $(21,22)$. Co-staining with anti- $\alpha$-SMA antibodies revealed that the tunica media of arteries and veins was generally negative for ephrinB2 (Fig. $1 M-O$ ). Note that a yellow signal indicating double positivity is seen only when intima and media are superimposed.

We then studied expression of the receptor EphB4 in vessels that were co-stained with PAL-E and CD31 (Fig. 2). The EphB4 antiserum was raised against the SAM domain and did not cross-react with other Eph receptors (data not shown). We observed expression of EphB4 in ECs of both PAL-E-positive veins (Fig. 2A-C) and in CD31-positive ECs of PAL-Enegative arteries (Fig. $2 D-F$ ). No immunoreactivity was detected in control sections that were incubated with preimmune antiserum or after omitting the primary antibody (data not 

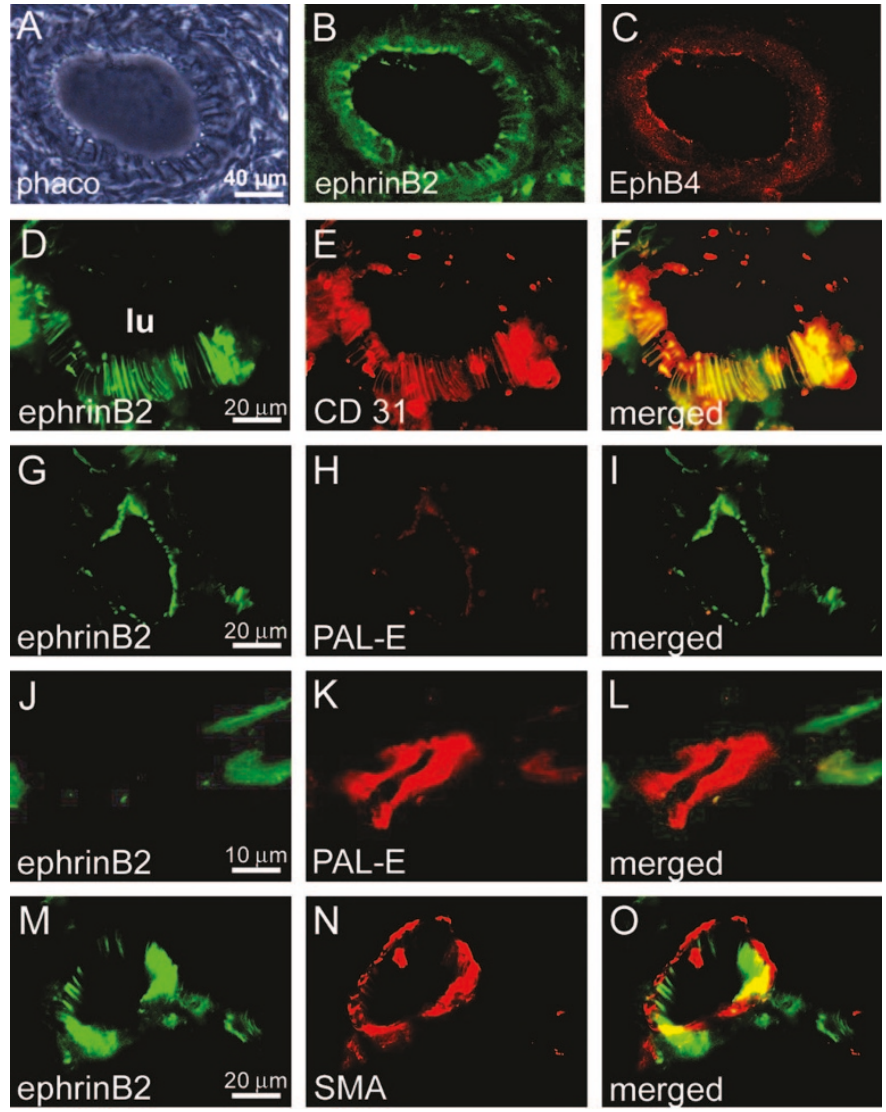

Figure 1. EphrinB2 expression in adult human blood vessels. Immunofluorescence co-staining of ephrinB2 (green) and EphB4 $(A-C), \mathrm{CD} 31(D-E)$, PAL-E $(G-L)$, or anti- $\alpha$-SMA $(M-O$; red). In an artery identified by phase contrast (phaco; $A$ ), there is ephrinB2 expression $(B)$ and also EphB4 $(C)$ in ECs. EphrinB2 is expressed in CD31-positive arterial endothelium $(D-F)$. Note the typical morphologic characteristics of arteries. The long axis of the ECs is orientated in the direction of the blood flow. The arteries are negative for PAL-E $(G-I)$. PAL-E-positive veins do not express ephrinB2 $(J-L)$. The co-staining with anti- $\alpha$-SMA antibodies demonstrates that the tunica media of arteries and veins is negative for ephrinB2 $(M-O)$. A pseudo-double positivity (yellow) is seen because in the $20-\mu \mathrm{m}$ cryosections, the tunica intima and media are superimposed. lu, lumen of the vessel.

shown). Therefore, in the human, like in other species, ephrinB2 is specifically expressed in arterial ECs, whereas in contrast to the mouse, EphB4 is a common marker for arterial and venous ECs.

We had previously described the expression of EphB2 in the vascular wall of mice (13), and we therefore investigated its expression in adult human tissues. EphB2 was stained with a specific antiserum raised against its SAM domain (19). No signal was detected in controls with preimmune antiserum or after omitting the primary antibody. We detected EphB2 in ECs that were identified by co-staining with CD31 (Fig. 3AC). EphB2 was expressed in the endothelium of PAL-Enegative arteries (Fig. 3D-F), which were additionally identified by their distinct tunica media and the longitudinal orientation of their ECs (Fig. 3G-L). EphB2 was absent from veins (Fig. $3 J-L$, arrow), and detected the receptor in neither arterial nor venous smooth muscle cell (SMCs; Fig. 3J-L). Because of its specific localization in arterial ECs, it is possible
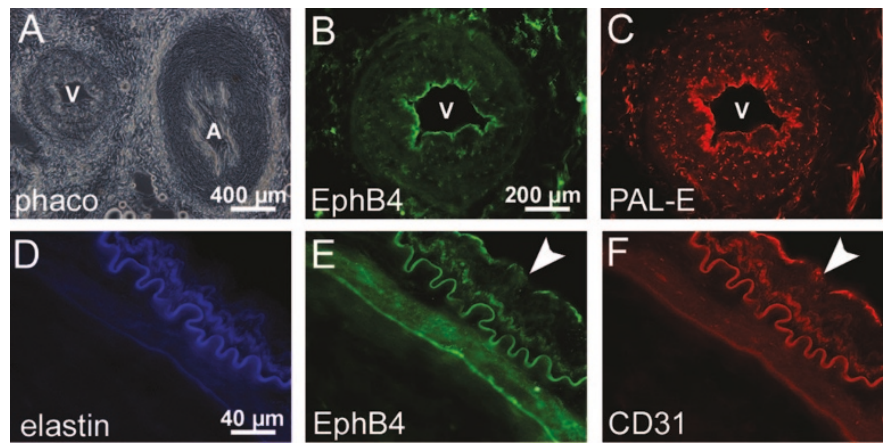

Figure 2. EphB4 expression in adult human arteries and veins. Branches of the fibular artery (a) and vein (v) identified by phase contrast (phaco; $A$ ). Immunofluorescence staining with antibodies against the SAM domain of EphB4 (green) in combination with PAL-E $(B$ and $C)$ and CD31 $(D-F)$ shown in red. EphB4 is expressed in PAL-E-positive veins $(B$ and $C$ ) and in PAL-E-negative arteries (see also Fig. $1 C$ ). EphB4 is found in the CD31positive endothelium (arrowhead) of arteries $(D-F)$. Note autofluorescence of elastic lamellae $(D)$.

to discriminate arteries from veins with EphB2 antibodies. The results are summarized in Table 1 .

In human umbilical cord, ephrinB2 and EphB4 are expressed in both arteries and veins, whereas EphB2 is specific for arterial ECs. Arterial and venous ECs from human umbilical cord vessels are widely used for in vitro studies. We therefore used cryosections of human umbilical cords to investigate the expression pattern of ephrinB2, EphB4, and EphB2 in situ. The human umbilical cord at term contains two arteries and one vein. Umbilical arteries convey deoxygenated blood and metabolites from the embryo toward the placenta. From there, oxygenated blood and nutrients flow back to the embryo through the umbilical vein. Morphologically, umbilical arteries can be distinguished from the umbilical vein by the strong postnatal contraction (23). In serial sections, we observed ephrinB2 co-expression with the pan-endothelial marker CD31 in arteries and veins (Fig. 4A-G). In addition, a subpopulation of venous SMCs were positive for ephrinB2, whereas the arterial smooth musculature showed no expression of the ligand (Fig. $4 H-L$ ).

The EphB4 antiserum homogeneously stained the endothelium of both umbilical arteries and umbilical vein with almost equal intensities (Fig. 5A-I). The SMC layers of neither umbilical arteries nor the umbilical vein expressed the receptor (Fig. $5 J-O$ ). The expression pattern does not differ from that of adult human vessels.

Staining of human umbilical cord with EphB2 antiserum revealed a complementary expression pattern in arteries and veins. In umbilical arteries, EphB2 expression was observed in ECs, as shown by co-staining with CD31 (Fig. 6A-F), and the signal was distributed evenly in the entire endothelium. In addition, positive staining of SMCs was found in the most peripheral layers of the tunica media (Fig. $6 A-C$ ), whereas SMCs adjacent to the endothelium displayed no EphB2 expression (Fig. 6G-I). In the umbilical vein, immunofluorescence double staining for EphB2 and CD31 revealed no expression of the receptor in the endothelium (Fig. $6 J-L$ ). In contrast, very strong expression of EphB2 was observed in the 

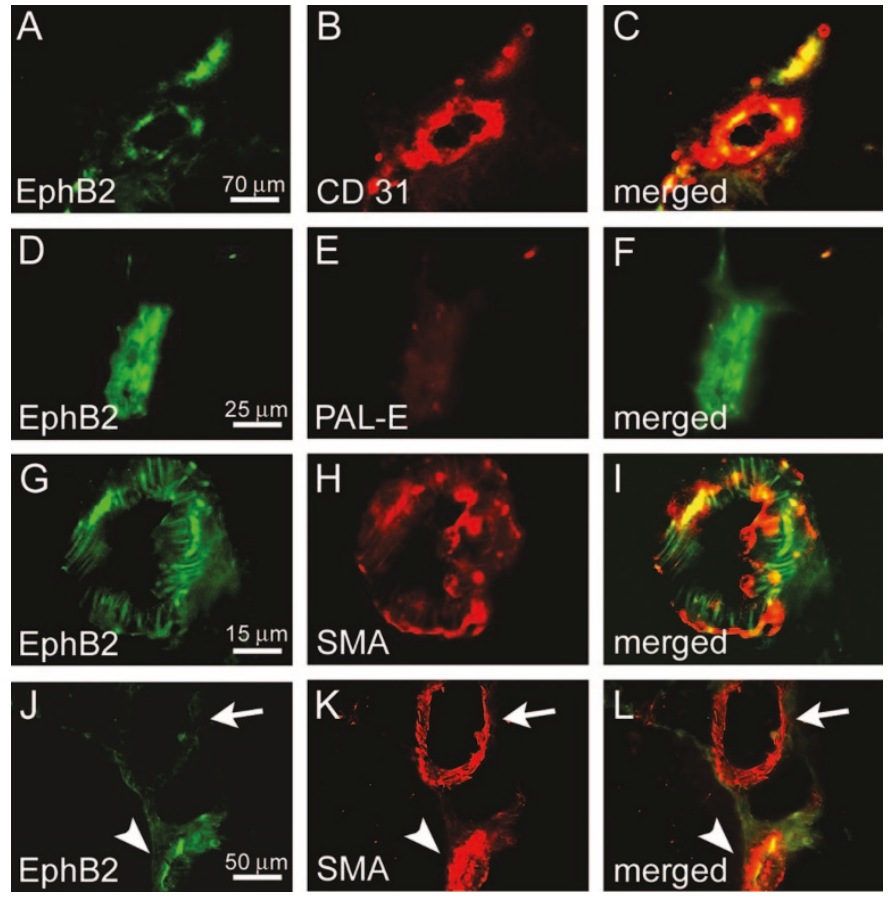

Figure 3. EphB2 expression in adult human arteries. Immunofluorescence staining with antibodies against EphB2 (green) in combination with CD31 $(A-C)$, PAL-E $(D-F)$, and anti- $\alpha$-SMA $(G-L$; red). The staining demonstrates EphB2 expression in the CD31-positive endothelium $(A-C)$. EphB2 is restricted to arteries, which are negative for PAL-E $(D-F)$. The co-staining with anti- $\alpha$-SMA antibodies demonstrates that the tunica media of arteries and veins is negative for EphB2 $(G-L)$. The yellow pseudo-double positivity appears only when the two cell layers are superimposed. For the EphB2 positive vessels, note also the typical morphologic characteristics of arteries. The long axis of the ECs is orientated in the direction of the blood flow $(G-I)$, and there is strong contraction of the arterioles (arrowhead in $J-L$ ). The vein has a wide lumen (arrow in $J-L$ ).

entire tunica media as demonstrated by co-staining with anti$\alpha$-SMA antibodies (Fig. $6 M-O$ ). The results are summarized in Table 1.

In venous malformations, arterial markers are expressed in venous ECs. To date, the classification of malformations is based on angiographic, intraoperative, and histologic findings $(24,25)$. In most cases, various types of blood vessels are involved. The Hamburg Classification for congenital vascular malformations distinguishes from among 1) predominantly arterial, 2) predominantly venous, 3) predominantly arteriovenous, 4) predominantly lymphatic malformations, and 5) combined forms $(26,27)$. Molecular markers to discriminate between different types of congenital vascular malformations are lacking. Here, we have studied the expression of ephrinB2, EphB4, EphB2, and PAL-E in venous malformations. PAL-E retained its venous specificity, and, like in normal tissue, arteries were not stained (Fig. 7). We observed deregulated expression of the arterial markers compared with the normal human vasculature. PAL-E-positive malformed veins showed abnormal expression of the arterial markers ephrinB2 (Fig. $7 A-C$, arrow, and $D-F$ ) and EphB2 (Fig. 7G-I). Surprising, down-regulation of arterial markers was observed in accompanying arteries, which were normal according to clinical parameters. The PAL-E-negative arteries expressed neither EphB2 nor ephrinB2 (Fig. 7A-C, arrowheads). The expression pattern of EphB4 seemed basically unaltered. Malformed veins continued to express EphB4 (Fig. $7 J-L$, arrows), and arteries were weakly positive (Fig. $7 J-L$, arrowheads). The results are summarized in Table 1.

In malformed veins, intima proliferations display arterial characteristics. In large malformed veins, we observed intima proliferations, which contain $\alpha$-SMA-positive cells (myofibroblasts, SMCs) and in-growing microvessels. We performed double staining with antibodies against ephrinB2, EphB4, or EphB2 (green) in combination with PAL-E or anti- $\alpha$-SMA (red). All ECs covering the intima proliferations were positive for PAL-E, indicating their venous character (Fig. $8 D-F$ and $J-L$ ), but additionally these ECs co-expressed the arterial markers ephrinB2 and EphB2. Remarkably, expression of ephrinB2 was strongest in ECs, which were in close contact to $\alpha$-SMA-positive cells (Fig. 8A-C). EphB2 expression in ECs mostly seemed to be independent from the proximity to $\alpha$-SMA-positive cells (Fig. 8G-I), and for EphB4 expression there was no correlation with the proximity to $\alpha$-SMA-positive cells (Fig. 8M-O). In $\alpha$-SMA-positive cells of intima proliferations, we never observed ephrinB2 or EphB2 (Fig. 8A-C and $G-I$ ). The up-regulation of arterial markers in malformed veins seems to be restricted on the endothelium.

\section{DISCUSSION}

Functions of ephrins during embryonic development. The Eph receptors comprise the largest subfamily of receptor tyrosine kinases, including at least 14 members in both human and mouse. The EphA subgroup consists of eight members, and the EphB subgroup consists of six members $(8,21)$. Membrane attachment and clustering of the ligands seem to be critical for the activation of the receptors (28). In addition, there is bidirectional signaling of ephrinB ligands. Upon receptor binding, the cytoplasmic domain of ephrinBs becomes phosphorylated, resulting in signaling toward both the receptor and the ligand expressing cells (29). During embryogenesis, ephrins confer positional information, often or mainly by repulsive activities. Ephrins are expressed in specific rhombomeres, where they are involved in boundary formation and neural crest cell guidance $(30,31)$. They also have a role in guiding axon growth and fasciculation (32). A collapsing activity for growth cones of axons has been observed as a result of interactions between ephrinA5 and EphA receptors (33). Boundary formation activity of ephrins has also been found in the paraxial mesoderm, where they control the metameric pattern of the somites (34).

Molecular background of hereditary vascular malformations. The cause of vascular malformations is largely unknown, and only in a few cases of hereditary vascular malformations has the molecular background been identified. In cerebral cavernous malformation, a vascular lesion with predilection to the brain, the mutated gene has been identified as Krev1 Interaction Trapped1 (KRIT1) $(35,36)$, a molecule of unknown function. Mucocutaneous venous malformations are distended channels often lacking support by vascular SMCs. In a family with autosomal dominant inheritance of the disease, a mutation 
Table 1. Expression of ephrinB2, EphB2, and EphB4 in ECs

\begin{tabular}{|c|c|c|c|c|c|}
\hline & $\begin{array}{c}\text { Normal } \\
\text { artery }\end{array}$ & Normal vein & $\begin{array}{c}\text { Umbilical } \\
\text { artery }\end{array}$ & $\begin{array}{c}\text { Umbilical } \\
\text { vein }\end{array}$ & $\begin{array}{c}\text { Malformed } \\
\text { vein }\end{array}$ \\
\hline EphrinB2 & ++ & - & ++ & ++ & ++ \\
\hline EphB2 & ++ & - & ++ & - & ++ \\
\hline EphB4 & + & ++ & ++ & ++ & ++ \\
\hline
\end{tabular}

+ present; + + strongly present; - absent.
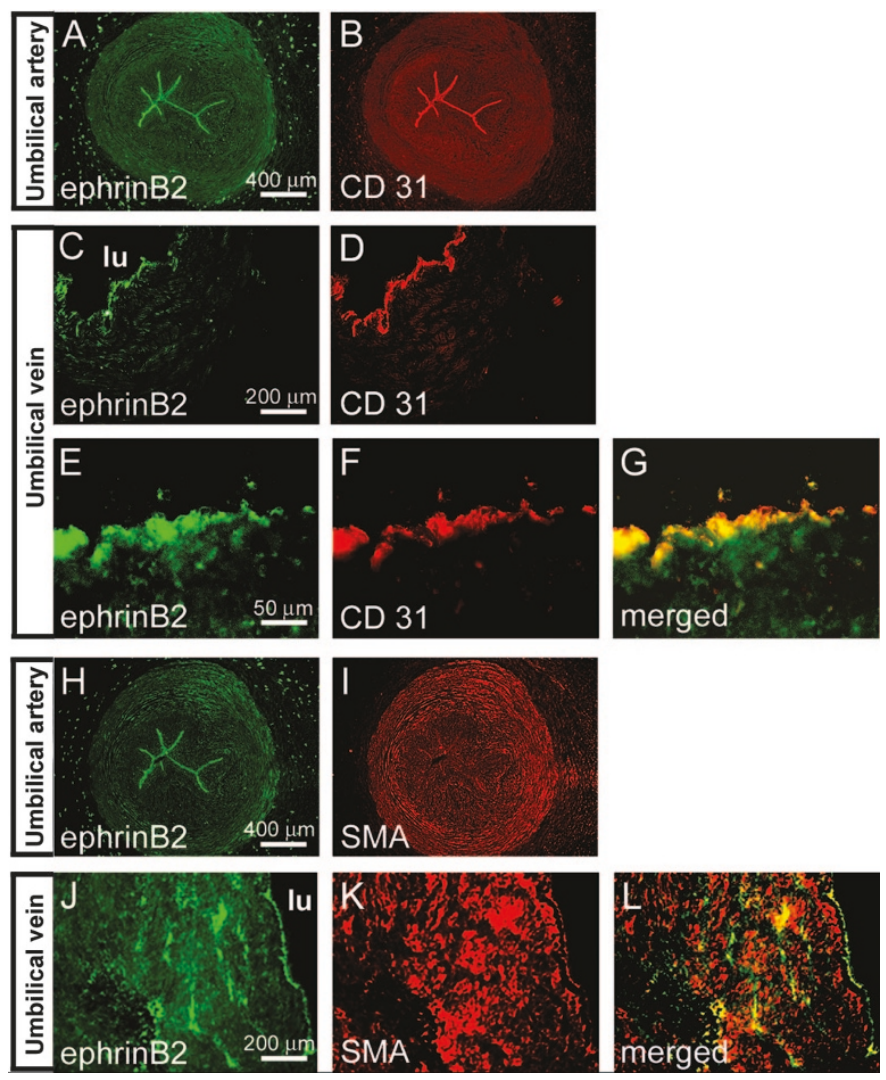

Figure 4. EphrinB2 expression in the human umbilical cord. Immunofluorescence co-staining of ephrinB2 (green) and CD31 $(A-G)$ or anti- $\alpha$-SMA $(H-L$; red). There is ephrinB2 expression in the endothelium of both the umbilical arteries and the umbilical vein $(A-G)$. Whereas the arterial smooth musculature does not express ephrinB2 ( $H$ and $I$ ), a subpopulation of venous SMCs are positive for ephrinB2 (yellow signal in $L$ ). lu, lumen of the vessel.

has been identified in the angiopoietin receptor TIE2/TEK (37). The mutation causes a ligand-independent activation of the receptor. Molecular genetic linkage analyses of glomuvenous malformations have identified a mutated gene on chromosome 1p21-p22, which was thereafter named glomulin (38). Glomulin might be involved in the transforming growth factor- $\beta$ signaling pathway. No other molecular data on arteriovenous and venous malformations have been reported yet.

Functions of ephrins in the vascular system: pathologic arterialization. The important functions of ephrinB2 and EphB4 for the development of arteries and veins have been demonstrated in knockout mice $(21,39)$. Except for one study on ephrinA/EphA interactions in tumor blood vessels (40), their roles in adult mice and humans have not been established. In this report, we have observed that specific members of the ephrin/Eph family continue to be expressed in differentiated human vasculature. EphrinB2 is a marker of arterial ECs. This
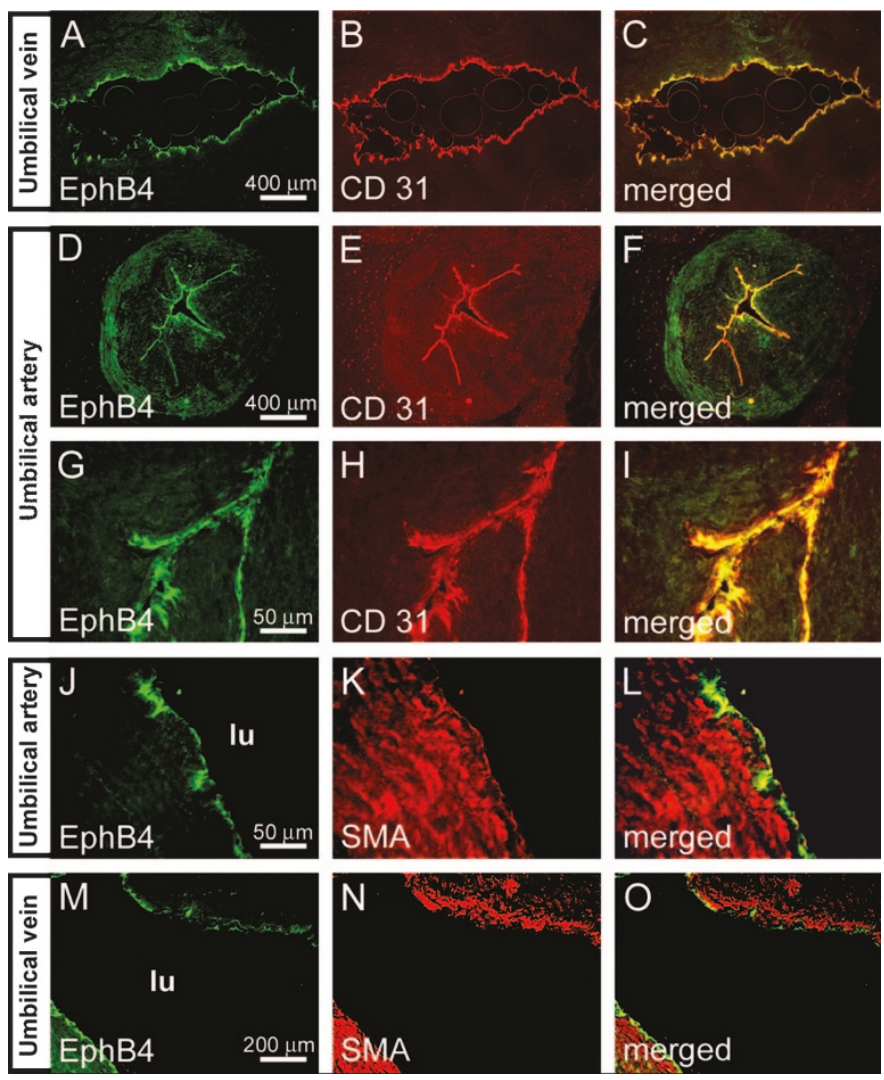

Figure 5. EphB4 expression in the human umbilical arteries and veins. Immunofluorescence staining with antibodies against EphB4 (green) in combination with CD31 $(A-I)$ or anti- $\alpha$-SMA $(J-O$; red). The staining shows EphB4 expression in the endothelium of both the umbilical vein $(A-C)$ and the umbilical arteries $(D-I)$. The staining intensity is almost the same in both types of vessels. Co-staining with anti- $\alpha$-SMA antibodies demonstrates that the SMC layers neither of umbilical arteries $(J-L)$ nor of the umbilical vein $(M-O)$ express EphB4. lu, lumen of the vessel.

expression pattern is similar to that in mice, chicks, and zebrafish $(21,22)$. EphB4 is expressed on human arteries and veins. In mice, EphB4 first was described as a venous marker (12), although weak expression on arteries was reported later (41). Nevertheless, there is a quantitative difference of EphB4 expression on arteries and veins in mice. Our immunohistologic studies show that this also seems to be the case in human tissues. In addition, our studies have revealed a new specific endothelial marker: EphB2 is expressed selectively in arterial ECs in the human, both in vessels of the adult and in the umbilicus. In mice, a different expression pattern has been described: peri-ECs and the myocardium being EphB2 positive $(13,42)$.

The functions of ephrins in the vascular system are not well understood. Boundary formation and repulsive or collapsing activities, like in the paraxial mesoderm and the nervous 


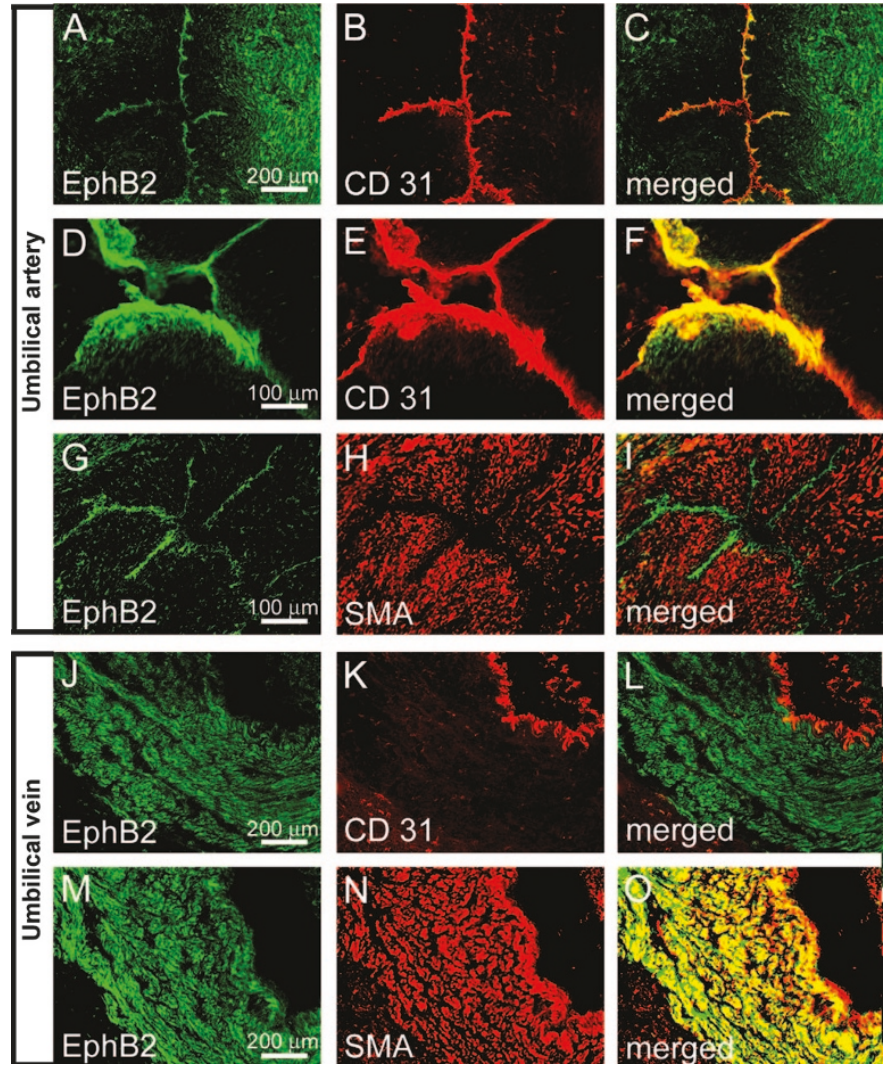

Figure 6. Specific EphB2 expression in ECs of the human umbilical artery. Immunofluorescence staining with antibodies against EphB2 (green) in combination with CD31 or anti- $\alpha$-SMA (red). In the umbilical artery there is EphB2 expression in the CD31-positive endothelium $(A-F)$. In addition, SMCs in the most peripheral layers of the tunica media express EphB2 $(A-C)$, whereas SMCs adjacent to the endothelium display no EphB2 expression $(G-I)$. In the umbilical vein, the endothelium is EphB2 negative $(J-L)$. In contrast, very strong and homogeneous expression is observed in the entire tunica media $(M-O)$

system, might destroy the continuity and integrity of the circulatory system. However, ephrins may provide positional information for the arterial and venous leg of the vasculature. Such information may be crucial not only during development but also for stabilization and regeneration. It was shown some time ago that, during wound healing, arteries connect to arteries, veins to veins, and lymphatics to lymphatics (43). In this scenario, repulsive mechanisms and positional information may be crucial to establish homophilic connections. In fact, recent studies have shown that EphB4 forward signaling restricts intermingling of different EC types. Thereby, ephrins regulate $\mathrm{EC}-\mathrm{EC}$ and $\mathrm{EC}-$ matrix adhesion, which is a prerequisite for migration, sprouting, and intercalated vascular growth (44). It has often been observed that vascular malformations expand upon injury. Abnormal expression of ephrins in vascular malformations may induce prolonged migration and sprouting of ECs and may also retard the formation of homophilic vascular connections.

The expression patterns of ephrinB2, EphB2, and EphB4 in vessels of the adult human suggest physiologic functions in differentiated vessels, which is supported by our finding of their deregulation in venous malformations. We have observed up-regulation of arterial markers ephrinB2 and EphB2 in af-
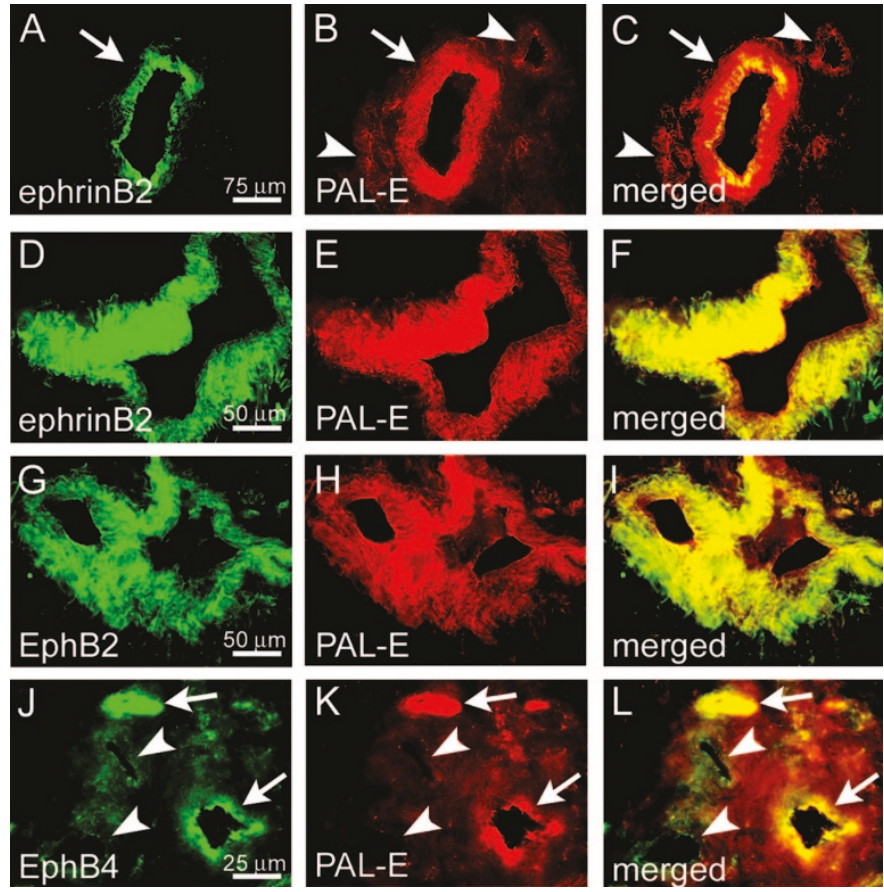

Figure 7. EphrinB2, EphB2, and EphB4 expression in venous malformations. Immunofluorescence co-staining of the ligand ephrinB2 or the receptors EphB2 and EphB4 (green) with PAL-E (red). In the lesions, PAL-E retains its venous specificity (arrow in $A-C$ ); therefore, arteries are not stained significantly (arrowheads in $B$ and $C$ ). There is ectopic expression of the arterial marker ephrinB2 in PAL-E-positive malformed veins $(A-F)$. Surprising, PAL-E-negative arteries do not express ephrinB2 (arrowheads in $B$ and $C$ ). The arterial marker EphB2 is also found in malformed PAL-E-positive veins $(G-I)$. EphB4 is expressed in the endothelium of malformed veins (arrows in $J-L$ ), whereas adjacent arteries are not or only weakly positive (arrowheads in $J-L)$.

fected veins. This may alter the behavior of ECs, leading to abnormal growth and patterning of vessels. It seems that the veins gradually become arterialized. Because the malformed veins in our study were of low-flow type, it seems that we can exclude that mechanical factors such as arterial shear stress and tangential (pulsatile) stress may have induced this process. However, the effects of turbulent blood flow cannot be excluded. Expression of ephrinB2 and EphB2 reflects arterialization of the affected veins, and it remains to be studied whether high-flow-type venous malformations are characterized by an even more pronounced arterialization.

Functions of ephrins in the vascular system: physiologic arterialization. In the umbilical cord, we have observed that the arterial marker ephrinB2 is expressed in the endothelium of both the umbilical vein and the umbilical artery, and only EphB2 is a specific marker of arterial ECs in the umbilicus. Our data suggest that changes of arterial and venous identity of vessels can occur not only under pathologic but also under physiologic conditions. Correspondingly, it has been shown that during embryonic development, venous ECs can transdifferentiate into arterial ECs (22). The stimuli that induce transdifferentiation of vessels may originate from the luminal side of the vessel or from the abluminal side as a result of interactions between ECs and peri-ECs. In venous malformations, we have observed strongest expression of ephrinB2 in ECs, which 

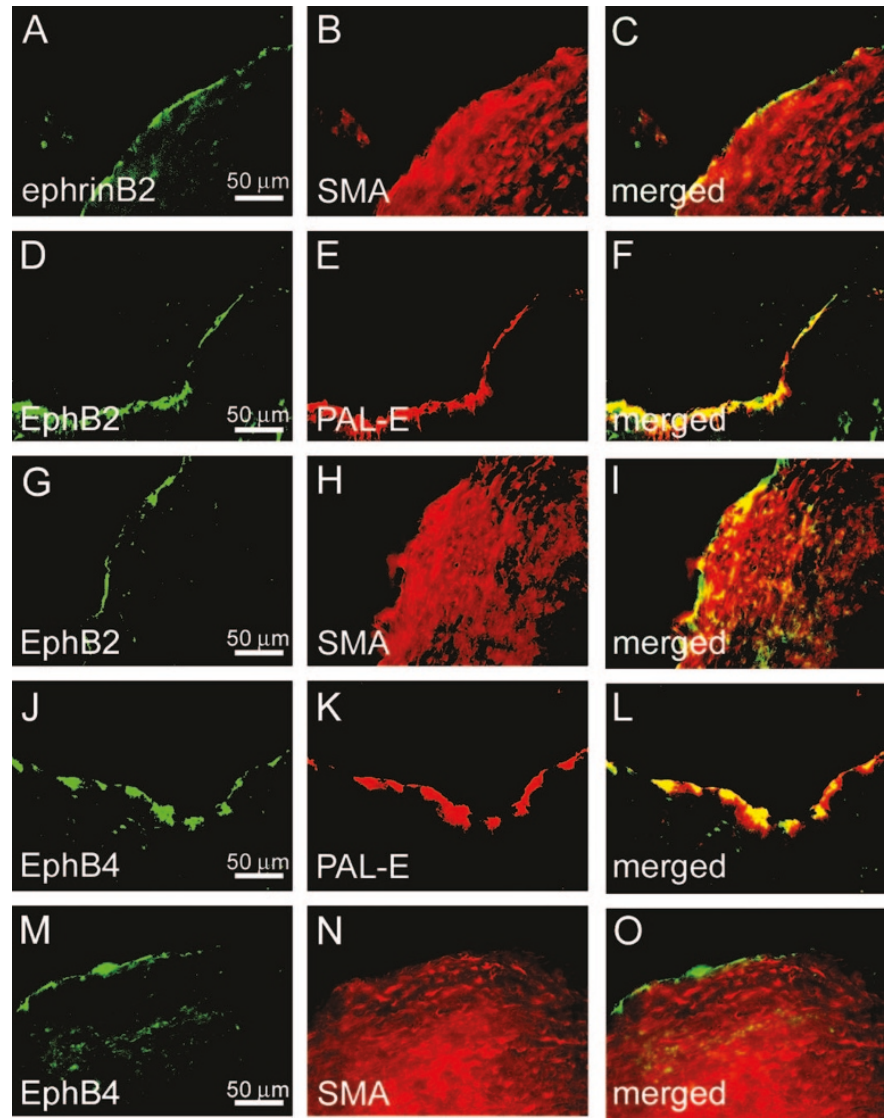

Figure 8. EphrinB2, EphB2, and EphB4 expression in intima proliferations of malformed veins. Immunofluorescence staining with antibodies against ephrinB2, EphB2, or EphB4 (green) in combination with anti- $\alpha$-SMA or PAL-E (red). The ECs co-express the arterial markers ephrinB2 $(A-C)$ and EphB2 $(D-I)$, as well as EphB4 $(J-O)$. The ECs also express PAL-E $(D-F$ and $J-L)$, indicating their venous character. The expression of ephrinB2 is strongest in ECs, which are in intimate contact with $\alpha$-SMA-positive cells $(A-C)$. EphB2 expression in ECs mostly seems to be independent from the proximity to $\alpha$-SMA-positive cells $(G-I)$, and EphB4 expression shows no correlation with the proximity to $\alpha$-SMA-positive cells $(M-O)$. Neither the ligand ephrinB2 $(A-C)$ nor the receptors EphB2 $(G-I)$ and EphB4 $(M-O)$ are expressed in $\alpha$-SMA-positive cells of intima proliferations.

are in intimate contact with $\alpha$-SMA-positive cells, supporting an influence from the abluminal side. In addition, influences from the luminal side of the vessel can be many-fold. In the umbilical vein, there is high pressure of $\mathrm{O}_{2}$ and in the umbilical arteries low pressure of $\mathrm{O}_{2}$, which may be responsible for the regulation of arterial and venous markers. Besides the shear stress and the transmural pressure, the tangential stress of the arterial system has a strong impact on the vessel wall (45). It induces hyperplasia of veins grafted into the arterial system, but its effect on the expressions of ephrins has not been studied yet.

In summary, our studies show that specific members of the ephrin/Eph family are expressed in the human vasculature and may be involved in the determination of arterial and venous phenotypes of vessels. EphrinB2 and EphB2 are specific markers of arterial ECs in the adult, whereas only EphB2 is specific for arterial ECs in the umbilical cord. Alterations of the expression patterns seem to coincide with changes of arterial and venous identities under both physiologic and pathologic conditions, but the cause for the altered expression patterns remains to be studied.

\section{REFERENCES}

1. Coffin JD, Poole TJ 1988 Embryonic vascular development: immunohistochemical identification of the origin and subsequent morphogenesis of the major vessel primordia in quail embryos. Development 102:735-748

2. Risau W 1997 Mechanisms of angiogenesis. Nature 386:671-674

3. Risau W, Flamme I 1995 Vasculogenesis. Annu Rev Cell Dev Biol 11:73-91

4. Sherer GK 1991 Vasculogenic mechanisms and epithelio-mesenchymal specificity in endodermal organs. Issues Biomed 14:37-57

5. Wilting J, Brand-Saberi B, Kurz H, Christ B 1995 Development of the embryonic vascular system. Cell Mol Biol Res 41:219-232

6. Folkman J 1995 Angiogenesis in cancer, vascular, rheumatoid and other disease. Nat Med 1:27-31

7. Hanahan D, Folkman J 1996 Patterns and emerging mechanisms of the angiogenic switch during tumorigenesis. Cell 86:353-364

8. Gale NW, Yancopoulos GD 1999 Growth factors acting via endothelial cell-specific receptor tyrosine kinases: VEGFs, angiopoietins, and ephrins in vascular development. Genes Dev 13:1055-1066

9. Adams RH 2002 Vascular patterning by Eph receptor tyrosine kinases and ephrins. Semin Cell Dev Biol 13:55-60

10. Kullander K, Klein R 2002 Mechanisms and functions of Eph and ephrin signalling. Nat Rev Mol Cell Biol 3:475-486

11. Palmer A, Klein R 2003 Multiple roles of ephrins in morphogenesis, neuronal networking, and brain function. Genes Dev 17:1429-1450

12. Wang HU, Chen ZF, Anderson DJ 1998 Molecular distinction and angiogenic interaction between embryonic arteries and veins revealed by ephrin-B2 and its receptor Eph-B4. Cell 93:741-753

13. Adams RH, Wilkinson GA, Weiss C, Diella F, Gale NW, Deutsch U, Risau W, Klein R 1999 Roles of ephrinB ligands and EphB receptors in cardiovascular development: demarcation of arterial/venous domains, vascular morphogenesis, and sprouting angiogenesis. Genes Dev 13:295-306

14. Cheng N, Brantley DM, Chen J 2002 The ephrins and Eph receptors in angiogenesis. Cytokine Growth Factor Rev 13:75-85

15. Nakamoto M, Bergemann AD 2002 Diverse roles for the Eph family of receptor tyrosine kinases in carcinogenesis. Microsc Res Tech 59:58-67

16. Fishman SJ, Mulliken JB 1993 Hemangiomas and vascular malformations of infancy and childhood. Pediatr Clin North Am 40:1177-1200

17. Landthaler M, Vogt T, Hohenleutner U 2002 Clinical and histological classification of benign vascular malformations and tumors of the skin. In: Landthaler M, Hohenleutner U, Vogt T (eds) Benign Vascular Malformations and Tumors of the Skin. Blackwell Verlag, Berlin, pp 31-43

18. Schlingemann RO, Dingjan GM, Emeis JJ, Blok J, Warnaar SO, Ruiter DJ 1985 Monoclonal antibody PAL-E specific for endothelium. Lab Invest 52:71-76

19. Grunwald IC, Korte M, Wolfer D, Wilkinson GA, Unsicker K, Lipp HP, Bonhoeffer T, Klein R 2001 Kinase-independent requirement of EphB2 receptors in hippocampal synaptic plasticity. Neuron 32:1027-1040

20. Wilting J, Papoutsi M, Christ B, Nicolaides KH, von Kaisenberg CS, Borges J, Stark GB, Alitalo K, Tomarev SI, Niemeyer C, Rossler J 2002 The transcription factor Prox 1 is a marker for lymphatic endothelial cells in normal and diseased human tissues. FASEB J 16:1271-1273

21. Adams RH, Klein R 2000 Eph receptors and ephrin ligands. Essential mediators of vascular development. Trends Cardiovasc Med 10:183-188

22. Othman-Hassan K, Patel K, Papoutsi M, Rodriguez-Niedenfür M, Christ B, Wilting J 2001 Arterial identity of endothelial cells is controlled by local cues. Dev Biol 237:398-409

23. Schiebler TH, Schmidt W, Zilles K 1999 Anatomie. Springer-Verlag, Berlin, pp 126-127

24. Belov S 1990 Classification of congenital vascular defects. Int Angiol 9:141-146

25. Belov S 1993 Anatomopathological classification of congenital vascular defects. Semin Vasc Surg 6:219-224

26. Leu HJ 1989 Pathoanatomy of congenital vascular malformations. Period Angiol 16:37-45

27. Leu HJ 1990 Pathomorphology of vascular malformations. Analysis of 310 cases. Int Angiol 9:147-154

28. Davis S, Gale NW, Aldrich TH, Maisonpierre PC, Lhotak V, Pawson T, Goldfarb M, Yancopoulos GD 1994 Ligands for EPH-related receptor tyrosine kinases that require membrane attachment or clustering for activity. Science 266:816-819

29. Brückner K, Klein R 1998 Signalling by Eph receptors and their ephrin ligands. Curr Opin Neurobiol 8:375-382

30. Becker N, Seitanidou T, Murphy P, Mattei MG, Topilko P, Nieto MA, Wilkinson DG, Charnay P, Gilardi-Hebenstreit P 1994 Several receptor tyrosine kinase genes of the Eph family are segmentally expressed in the developing hindbrain. Mech Dev 47:3-17

31. Smith A, Robinson F, Patel K, Wilkinson DG 1997 The EphA4 and EphB1 receptor tyrosine kinases and ephrin-B2 ligand regulate targeted migration of branchial neural crest cells. Curr Biol 1:561-570

32. Gao PP, Zhang JH, Yokoyama M, Racey B, Dreyfus CF, Black IB, Zhou R 1996 Regulation of topographic projection in the brain: Elf-1 in the hippocamposeptal system. Proc Natl Acad Sci USA 93:11161-11166

33. Drescher U, Kremoser C, Handwerker C, Loschinger J, Noda M, Bonhoeffer F 1995 In vitro guidance of retinal ganglion cell axons by RAGS, a $25 \mathrm{kDa}$ tectal protein related to the ligands for Eph receptor tyrosine kinases. Cell 82:359-370 
34. Stockdale FE, Nikovits W Jr, Christ B 2000 Molecular and cellular biology of avian somite development. Dev Dyn 219:304-321

35. Laberge-le Couteulx S, Jung HH, Labauge P, Houtteville JP, Lescoat C, Cecillon M, Marechal E, Joutel A, Bach JF, Tournier-Lasserve E 1999 Truncating mutations in CCM1, encoding KRIT1, cause hereditary cavernous angiomas. Nat Genet 23:189-193

36. Serebriiskii I, Estojak J, Sonoda G, Testa JR, Golemis EA 1997 Association of Krev-1/rap1a with Krit1, a novel ankyrin repeat-containing protein encoded by a gene mapping to 7q21-22. Oncogene 15:1043-1049

37. Vikkula M, Boon LM, Carraway KL 3rd, Calvert JT, Diamonti AJ, Goumnerov B, Pasyk KA, Marchuk DA, Warman ML, Cantley LC, Mulliken JB, Olsen BR 1996 Vascular dysmorphogenesis caused by an activating mutation in the receptor tyrosine kinase TIE2. Cell 87:1181-1190

38. Brouillard P, Olsen BR, Vikkula M 2000 High-resolution physical and transcript map of the locus for venous malformations with glomus cells (VMGLOM) on chromosome 1p21-p22. Genomics 67:96-101

39. Gerety SS, Anderson DJ 2002 Cardiovascular ephrinB2 function is essential for embryonic angiogenesis. Development 129:1397-1410
40. Brantley DM, Cheng N, Thompson EJ, Lin Q, Brekken RA, Thorpe PE, Muraoka RS, Cerretti DP, Pozzi A, Jackson D, Lin C, Chen J 2002 Soluble Eph A receptors inhibit tumor angiogenesis and progression in vivo. Oncogene 21:7011-7026

41. Gerety SS, Wang HU, Chen ZF, Anderson DJ 1999 Symmetrical mutant phenotypes of the receptor EphB4 and its specific transmembrane ligand ephrin-B2 in cardiovascular development. Mol Cell 4:403-414

42. Henkemeyer M, Orioli D, Henderson JT, Saxton TM, Roder J, Pawson T, Klein R 1996 Nuk controls pathfinding of commissural axons in the mammalian central nervous system. Cell 86:35-46

43. Pullinger DB, Florey HW 1937 Proliferation of lymphatics in inflammation. J Pathol Bacteriol 45:157-170

44. Fuller T, Korff T, Kilian A, Dandekar G, Augustin HG 2003 Forward EphB4 signaling in endothelial cells controls cellular repulsion and segregation from ephrinB2 positive cells. J Cell Sci 116:2461-2470

45. Zwolak RM, Adams MC, Clowes AW1987 Kinetics of vein graft hyperplasia: association with tangential stress. J Vasc Surg 5:126-136 